\title{
Larvicidal activity of the methanol extract and fractions of the green fruits of Solanum lycocarpum (Solanaceae) against the vector Culex quinquefasciatus (Diptera: Culicidae)
}

\author{
Thamer Matias Pereira ${ }^{[1]}$, Viviane de Cássia Bicalho Silva ${ }^{[1]}$, José Antônio Ribeiro Neto ${ }^{[1]}$, \\ Stênio Nunes Alves ${ }^{[1]}$ and Luciana Alves Rodrigues dos Santos Lima ${ }^{[1]}$
}

[1]. Campus Centro-Oeste Dona Lindu, Universidade Federal de São João Del-Rei, Divinópolis, MG.

\begin{abstract}
Introduction: The larvicidal activity of Solanum lycocarpum against Culex quinquefasciatus is unknown. Methods: We evaluated the larvicidal activity of extracts of the green fruits of Solanum lycocarpum against third and fourth instar larvae of C. quinquefasciatus. Results: Dichloromethane and ethyl acetate fractions showed the greatest larvicidal effect at $200 \mathrm{mg} / \mathrm{L}$ (83.3\% and $86.7 \%$, respectively). The methanol and dichloromethane, ethyl acetate, and hydromethanolic fractions demonstrated larvicidal effects against $C$. quinquefasciatus, with $\mathrm{LC}_{50}$ values of $126.24,75.13,83.15$, and 207.05mg/L, respectively. Conclusions: Thus, when considering new drugs with larvicidal activity from natural products, $S$. lycocarpum fruits may be good candidate sources.
\end{abstract}

Keywords: Bioassay. Mosquito. Pesticide.

The species Culex quinquefasciatus (Diptera: Culicidae) is a mosquito inhabiting urban regions, with a wide geographical distribution. This species is involved in the transmission of lymphatic filariasis in the Americas, particularly in Brazil. C. quinquefasciatus is of great importance in public health as it creates administrative and public challenges for the control of mosquito vectors ${ }^{1}$.

Synthetic insecticides have been widely used to control mosquito vectors of disease in various parts of the world; however, resistance to these insecticides has recently become problematic in vector control programs. Moreover, the continuous monitoring of mosquito populations may play an important role in attempting to develop management strategies that will prevent or minimize the development of resistance to pesticides, as well as to develop new products to combat insects ${ }^{2}$. Thus, the use of biological products is an alternative approach for preventing the development of resistance in mosquitoes.

Plants are a source of bioactive compounds that have insecticidal properties and therefore may be suitable for mosquito control ${ }^{3}$. Phytoextracts have previously been shown to be successful in various biocontrol programs, and essential

Address to: $\mathrm{Dr}^{\mathrm{a}}$ Luciana Alves Rodrigues dos Santos Lima. Campus CentroOeste Dona Lindu/UFSJ. Rua Sebastião Gonçalves Coelho 400, Chanadour, 35501-296 Divinópolis, MG, Brasil.

Phone: 5537 3071-1878; Fax: 5537 3221-1614

e-mail: luarsantos@ufsj.edu.br

Received 22 January 2014

Accepted 29 May 2014 oils of different plants are used as potential mosquito repellents. Different species of the genus Solanum have demonstrated larvicidal and pupicidal activities against $C$. quinquefasciatus ${ }^{4,5}$. The species Solanum lycocarpum A. St. Hil., belonging to the Solanaceae family, is popularly known as lobeira and is widely distributed in the Brazilian cerrado ${ }^{6}$. It is widely used in traditional medicine as a sedative, in the treatment of epilepsy, asthma, diabetes, obesity, for the reduction of cholesterol levels, and for abdominal and renal pain ${ }^{7}$.

To our knowledge, for the first time, we show the larvicidal activities of the extracts and fractions obtained from the green fruits of $S$. lycocarpum against $C$. quinquefasciatus.

The green fruits of S. lycocarpum A. St. Hil. were collected in the City of São Sebastião do Oeste, State of Minas Gerais, Brazil, in August 2011. The plant material was identified by Dr. Alexandre Salino, and a voucher specimen (BHCB 159397) was deposited at the Instituto de Ciências Biológicas Herbarium, Universidade Federal de Minas Gerais, Belo Horizonte, MG, Brazil. Methanol was used as solvent to obtain the extract from $170.01 \mathrm{~g}$ of dried and powdered green fruits, using a Soxhlet extractor. The extract was then concentrated in a rotary evaporator at $50^{\circ} \mathrm{C}$ under reduced pressure to yield the methanol extract (MET, 14.53g). Some of this extract $(6.82 \mathrm{~g})$ was dissolved in $\mathrm{MeOH} / \mathrm{H}_{2} \mathrm{O}(1: 1)$ and then partitioned successively with hexane, dichloromethane, and ethyl acetate (Vetec $\AA$, São Paulo, Brazil; $100 \mathrm{~mL}$, twice with each solvent), yielding 0.09, 0.23, 0.34, and $5.50 \mathrm{~g}$ of hexane (HEX), dichloromethane (DCM), ethyl acetate (AC), and hydromethanolic (HM) fractions, respectively. The extract and fractions were screened for the presence of different phytoconstituents such as saponins, tannins, alkaloids, steroids, triterpenes, coumarins, and flavonoids ${ }^{8}$. 
Culex quinquefasciatus larvae were obtained from a laboratory culture, as previously described by Gerberg ${ }^{9}$. Both the third and fourth instar larvae of C. quinquefasciatus were exposed to different concentrations $(12.5,50$, and $200 \mathrm{mg} / \mathrm{L}$; dissolved in $1 \%$ dimethylsulfoxide) of the methanol extract and fractions up to the emergence of adults, to determine the optimal sub-lethal concentration. For each sample tested, the larvae were divided into test and control groups, consisting of 60 specimens each, with three replications for each treatment. The control group larvae were exposed to water dissolved in $1 \%$ dimethylsulfoxide. The temperature was maintained at $26 \pm 1^{\circ} \mathrm{C}$ throughout all of the tests. The larvicidal bioassay was performed according to the World Health Organization standard protocols ${ }^{10}$. The larvae were exposed to these solutions, and mortality was recorded every $24 \mathrm{~h}$ over a total period of $144 \mathrm{~h}$. Three replications of each treatment were performed and the larvae used were all of the first generation. Larvae were considered dead when they did not respond to the stimulus or when they did not rise to the surface of the solution. $\mathrm{LC}_{50}$ and $\mathrm{LC}_{90}$ values were calculated by Probit regression ${ }^{11}$.

In this study, phytochemical tests revealed the presence of coumarins, flavonoids, and tannins in the methanol extract. Saponins were present in the dichloromethane fraction, while alkaloids and coumarins were found in the hexane fraction. On the other hand, flavonoids, coumarins, and tannins were found to be present in the dichloromethane, ethyl acetate, and hydromethanolic fractions, and terpenes/sterols were found in the dichloromethane and hydromethanolic fractions.

Larval mortality rates in each group, expressed as percentages, are shown in Figure 1. Analysis of variance tests, comparing the percentage of mortality between the various treatments, showed significant differences, depending on the concentrations and extracts or fractions used. Furthermore, a positive correlation was observed between the concentration of the methanol extract and fractions and the mortality rate (Figure 1), with the mortality rate being directly proportional to concentration. The dichloromethane and ethyl acetate fractions showed the greatest larvicidal effect at $200 \mathrm{mg} / \mathrm{L}(83.3 \%$ and $86.7 \%$, respectively), and was significantly different compared to the other treatments $(p<0.05)$. The greatest mortality was observed at $200 \mathrm{mg} / \mathrm{L}$ for the methanol extract $(66.7 \%)$ as well as for the hydromethanolic fraction $(51.7 \%)$. The hexane fraction did not show larvicidal activity, yielding values lower than $20 \%$ (Figure 1). No significant differences in mortality were observed for the ethyl acetate and hydromethanolic fractions at $12.5 \mathrm{mg} / \mathrm{L}$, the dichloromethane fraction at $12.5 \mathrm{mg} / \mathrm{L}$, the hexane fraction at $50 \mathrm{mg} / \mathrm{L}$, the hydromethanolic fraction at $50 \mathrm{mg} / \mathrm{L}$, and the hexane fraction at $200 \mathrm{mg} / \mathrm{L}$. There was a complete absence of larval mortality in the dimethylsulfoxide controls.

The pertinent values for the methanol extract and different fractions, estimated by the $\mathrm{LC}_{50}-\mathrm{LC}_{90}$ regression equation and chi-square tests, are presented in Table 1. The methanol extract and dichloromethane, ethyl acetate, and hydromethanolic fractions had larvicidal effects against $C$. quinquefasciatus, with $\mathrm{LC}_{50}$ values between 75.13 and $207.05 \mathrm{mg} / \mathrm{L}$; this represents higher larvicidal activity than that of other plant species of the

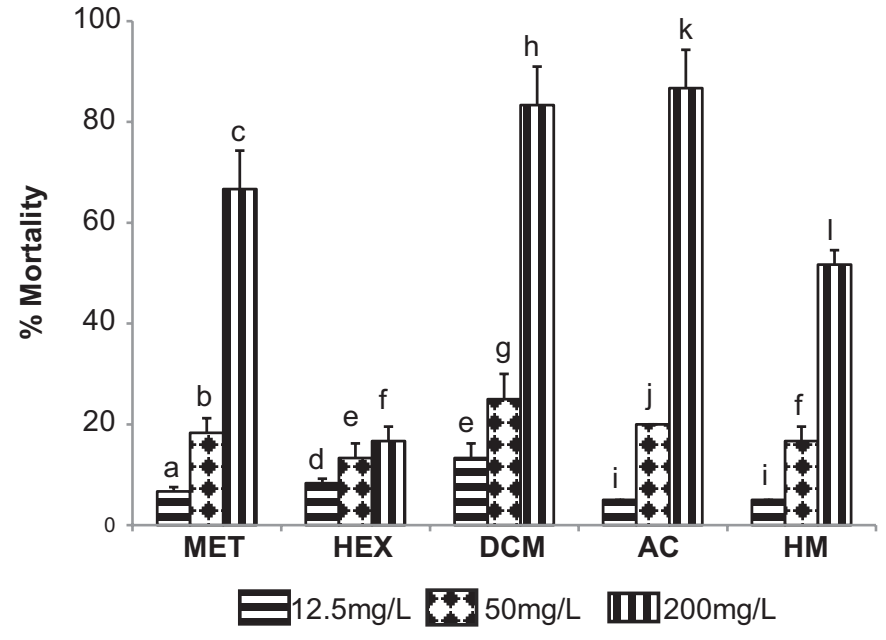

Different letters between columns indicate significant differences $(p<0.05)$ between treatments.

FIGURE 1 - Percentage larval mortality of Culex quinquefasciatus after exposure to different concentrations of the methanol extract and fractions of the green fruits of Solanum lycocarpum. MET: methanol extract; HEX: hexane fraction; DCM: dichloromethane fraction; AC: ethyl acetate fraction; HM: hydromethanolic fraction.

Solanum genus. For instance, ethanolic extracts of the leaves of S. xanthocarpum showed activity against the third and fourth instar larvae of C. quinquefasciatus, with $\mathrm{LC}_{50}$ values of 271.12 and $377.40 \mathrm{mg} / \mathrm{L}$, respectively ${ }^{4}$. However, the larvicidal activity of the methanol extract of S. lycocarpum reported in the present study are comparable to those achieved by Sakthivadivel and Daniel ${ }^{5}$, who demonstrated the larvicidal effect of the ethanolic extract of leaves of the S. trilobatum on the fourth instar larvae of C. quinquefasciatus, with $\mathrm{LC}_{50}>200 \mathrm{mg} / \mathrm{L}$.

In this study, the dichloromethane and ethyl acetate fractions showed the lowest $\mathrm{LC}_{90}$ values $(387.18$ and $271.57 \mathrm{mg} / \mathrm{L}$, respectively), making them the most toxic fractions against C. quinquefasciatus. The methanol extract and hydromethanolic fraction showed $\mathrm{LC}_{90}$ values of 709.53 and $1,743.57 \mathrm{mg} / \mathrm{L}$. Ethanolic extracts of the leaves of $S$. xanthocarpum also showed activity against the third and fourth instar larvae of C. quinquefasciatus, with $\mathrm{LC}_{90}$ values of $1,011.89$ and $1,058.85 \mathrm{mg} / \mathrm{L}$, respectively ${ }^{4}$. Changbunjong et al. ${ }^{12}$ also showed larvicidal activity of the ethanolic extract of green fruits of $S$. xanthocarpum against $C$. quinquefasciatus, with $\mathrm{LC}_{50}$ and $\mathrm{LC}_{90}$ values of 573.20 and $1,066.93 \mathrm{mg} / \mathrm{L}$, respectively, which were greater than those found in our study.

The effectiveness of the derived secondary compounds of a plant, such as saponins, steroids, isoflavonoids, and tannins have been well documented for their larvicidal activity ${ }^{13}$. Chowdhury et al. ${ }^{14}$ also evaluated the green berries of $S$. villosum, and suggested that a steroid compound was responsible for its observed larval toxicity. Thus, the higher larvicidal activity found in the dichloromethane fraction can be attributed, at least partially, to the action of saponins, steroids and tannins.

In conclusion, our preliminary results indicate that the methanol extract and dichloromethane, ethyl acetate, and 
TABLE 1 - Lethal concentrations of the methanol extract and fractions of the green fruits of Solanum lycocarpum against Culex quinquefasciatus.

\begin{tabular}{lcccr}
\hline Samples & $\begin{array}{c}\mathrm{LC}_{50}(95 \% \mathrm{CI}) \\
\mathrm{mg} / \mathrm{L}\end{array}$ & $\begin{array}{c}\mathrm{LC}_{90}(95 \% \mathrm{CI}) \\
\mathrm{mg} / \mathrm{L}\end{array}$ & Regression equations & $\chi^{2}$ \\
\hline MET & 126.24 & 709.53 & $y=1.568 x+1.629$ & 2.77 \\
& $(89.90-177.27)$ & $(346.17-1,454.31)$ & & 7.93 \\
\hline DCM & 75.13 & 387.18 & $y=1.748 x+1.757$ & 0.57 \\
& $(49.79-113.35)$ & $(188.73-794.29)$ & & 8.22 \\
\hline AC & 83.15 & 271.57 & $y=0.714 x+2.280$ & 0.62 \\
& $(60.69-113.91)$ & $(166.72-442.35)$ & & \\
\hline HM & 207.05 & $1,743.57$ & $y=2.008 x+1.283$ & 0.74
\end{tabular}

$\mathbf{L C}_{50}:$ median lethal concentration; CI: confidence interval; $\mathbf{L C}_{\mathbf{9 0}}: 90 \%$ lethal concentration; $\chi^{2}$ : chi-square value. MET: methanol extract; DCM: dichloromethane fraction; $\mathbf{A C}$ : ethyl acetate fraction; HM: hydromethanolic fraction; $\boldsymbol{y}:$ probit value; $\boldsymbol{x}$ : log concentration of the methanol extract and fractions of the green fruits.

hydromethanolic fractions of the green fruits of S. lycocarpum showed larvicidal activity against $C$. quinquefasciatus. These results form the basis for additional studies for evaluating the possibilities of using the extracts and fractions of green fruits of $S$. lycocarpum as natural, plant-based sources of larvicides.

\section{ACKNOWLEDGMENTS}

The authors are grateful to Prof. Dr. Alexandre Salino for botanical identification of this plant.

\section{CONFLICT OF INTEREST}

The authors declare that there is no conflict of interest.

\section{FINANCIAL SUPPORT}

The study was supported by Fundação de Amparo a Pesquisa do Estado de Minas Gerais (FAPEMIG) and the Coordenação de Aperfeiçoamento de Pessoal de Nivel Superior (CAPES).

\section{REFERENCES}

1. Campos J, Andrade CFS. Susceptibilidade larval de populações de Aedes aegypti e Culex quinquefasciatus a inseticidas químicos. Rev Saude Publica 2003; 37:523-527.

2. Alves SN, Tibúrcio JD, Melo AL. Susceptibility of Culex quinquefasciatus larvae to different insecticides. Rev Soc Bras Med Trop 2011; 44:486-489.
3. Prophiro JS, Rossi JCN, Pedroso MF, Kanis LA, Silva OS. Leaf extracts of Melia azedarach Linnaeus (Sapindales: Meliaceae) act as larvicide against Aedes aegypti (Linnaeus, 1762) (Diptera: Culicidae). Rev Soc Bras Med Trop 2008; 41:560-564.

4. Mahesh Kumar P, Murugan K, Kovendan K, Subramaniam J, Amaresan D. Mosquito larvicidal and pupicidal efficacy of Solanum xanthocarpum (Family: Solanaceae) leaf extract and bacterial insecticide, Bacillus thuringiensis, against Culex quinquefasciatus Say (Diptera: Culicidae). Parasitol Res 2012; 110:2541-2550.

5. Sakthivadivel M, Daniel T. Evaluation of certain insecticidal plants for the control of vector mosquitos viz. Culex quinquefasciatus, Anopheles stephensi and Aedes aegypti. Appl Entomol Zool 2008; 43:57-63.

6. Vieira Jr G, Ferreira PM, Matos LG, Ferreira EC, Rodovalho W, Ferri PH, et al. Anti-inflammatory effect of Solanum lycocarpum fruits. Phytother Res 2003; 17:892-896.

7. Munari CC, Oliveira PF, Lima IMS, Martins SPL, Costa JC, Bastos JK, et al. Evaluation of cytotoxic, genotoxic and antigenotoxic potential of Solanum lycocarpum fruits glicoalkaloid extract in V79 cells. J Food Chem Toxicol 2012; 50:3696-3701.

8. Wagner H, Bladt S, Zgainski EM. Plant drug analysis. A thin layer chromatography atlas. London: Springer; 2001.

9. Gerberg EJ. Manual for mosquito rearing and experimental techniques. Am Mosq Control Assoc 1979; 5:1-124.

10. World Health Organization. Instructions for determining the susceptibility or resistance of mosquito larvae to insecticides. Vector Biol Control 1981; 81.807:1-6.

11. Finney DJ. Probit analysis, a statistical treatment of the sigmoid response curve. Cambridge: Cambridge University Press; 1980.

12. Changbunjong T, Wongwit W, Leemingsawat S, Tongtokit $Y$, Deesin V. Effect of Solanum xanthocarpum against snails and mosquito larvae. Southeast Asian J Trop Med Public Health 2010; 41:320-325.

13. Singha S, Chandra G. Mosquito larvicidal activity of some common spices and vegetable waste on Culex quinquefasciatus and Anopheles stephensi. Asian Pac J Trop Med 2011; 4:288-293.

14. Chowdhury N, Ghosh A, Chandra G. Mosquito larvicidal activities of Solanum villosum berry extract against the dengue vector Stegomyia aegypti. BMC Complement Altern Med 2008; 8:1-8. 